\title{
Investigation and Analysis of Influencing Factors of Moderate to Severe Pain After Uterine Artery Embolization in Patients with Cesarean Scar Pregnancy
}

\author{
Cai-Feng $\operatorname{Lan}^{1, *}$ \\ Bi-Hua Lin ${ }^{2, *}$ \\ Cai-Ling $\mathrm{Nie}^{\prime}$ \\ Xiu-Ling Guo' \\ Dan-Hong Zhou' \\ Yan-Juan Lin (10 ${ }^{3}$ \\ 'Department of Gynecology and \\ Obstetrics, Fujian Medical University \\ Union Hospital, Fuzhou, 35000I, People's \\ Republic of China; ${ }^{2}$ Department of \\ Neurosurgery, Fujian Medical University \\ Union Hospital, Fuzhou, 35000I, People's \\ Republic of China; ${ }^{3}$ Nursing Department, \\ Fujian Medical University Union Hospital, \\ Fuzhou, 35000I, People's Republic of \\ China
}

*These authors contributed equally to this work
Correspondence: Yan-Juan Lin Nursing Department, Fujian Medical University Union Hospital, No. 29 of Xinquan Road, Gulou District, Fuzhou, 35000 I, Fujian, People's Republic of China Tel +8659186218332

Email yjlin689@I63.com
Objective: To investigate the occurrence and influencing factors of moderate to severe pain in patients with cesarean scar pregnancy (CSP) after uterine artery embolization (UAE).

Methods: Ninety-eight patients with CSP who underwent UAE in gynecology department of the Fujian Medical University Union Hospital from January 2017 to December 2020 were enrolled, and the specialty data in patients were collected for pain assessment with the adoption of the numerical rating scale (NRS).

Results: Moderate to severe pain occurred in 36 patients after surgery, and the interquartile of time to the first onset of postoperative pain in patients was $3.04(1.75,7.40)$ hours. The number of pregnancies, number of miscarriages, human chorionic gonadotropin (HCG) before curettage, duration of medication before UAE, and hemorrhage after UAE were not significantly correlated with the occurrence of moderate to severe pain after UAE $(\mathrm{P}>0.05)$. The volume of gestational sac and days of gestation were responsible for the occurrence of moderate to severe pain after UAE $(\mathrm{P}<0.05)$, with the former being the main influencing factor, and these explained $8.3 \%$ of the total variance.

Conclusion: Moderate to severe pain occurred commonly in patients with CSP undergoing UAE. In clinical care of patients with CSP who are going to undergo UAE, data concerning the volume of gestational sac and days of gestation should be considered for anticipatory pain assessment, and interventions should be implemented as early as possible to reduce the pain and improve the experience of care.

Keywords: cesarean scar pregnancy, uterine artery embolization, moderate to severe pain, research

\section{Introduction}

In recent years, with the liberalization of the second-child policy in China, the cesarean delivery rate has been increasing, leading to a significant increase in the incidence of cesarean scar pregnancy (CSP). ${ }^{1}$ CSP refers to a special type of ectopic pregnancy in which the fertilized egg implants in the uterine incision scar resulting from a previous cesarean delivery, but with a time-limited definition of early pregnancy. ${ }^{2}$ CSP is one of the long-term complications of cesarean delivery. ${ }^{3}$ Some literature also refers to this as "post-cesarean uterine scar pregnancy" or "scar pregnancy."

The occurrence of CSP often causes massive vaginal hemorrhaging and uterine rupturing in the late stage, making it one of the more difficult abnormal pregnancies 
to manage clinically. ${ }^{4}$ Moreover, because the embryo is implanted in the cesarean incision scar located in the lower uterine segment, the weak muscle wall tissue of the uterine scar area is easily penetrated during the growth and development of the fetal sac (implantation therein). ${ }^{5}$ Coupled with the lack of contractility of the cesarean incision scar, the broken blood vessels in patients with CSP cannot be closed naturally during abortion or curettage, and fatal massive hemorrhaging may occur. It has been reported that uterine artery embolization (UAE) has less bleeding than other surgical treatments. ${ }^{6}$

Pain is one of the main factors of surgical stress, which can aggravate insulin resistance, delay patients' early postoperative activities, increase the incidence of postoperative complications, prolong hospital stay, and may develop into chronic pain and reduce patients' postoperative quality of life. Pain management is an important content of ERAS. ${ }^{7}$ One of the main challenges of UAE is the management of postoperative pain, ${ }^{8}$ which has an incidence of $92.7 \%$, including $29.0 \%$ of severe pain, ${ }^{9}$ and which is mainly correlated with vasospasm caused by repeated irritation of the vessel wall or prolonged stay in the vessel of catheters and guidewires. ${ }^{10}$ Therefore, it is of great significance to be familiar with and master the factors of pain in patients undergoing UAE and properly foresee the implementation of intervention measures to improve the overall quality of patients during hospitalization and improve treatment satisfaction. UAE is widely adopted for patients with various gynecological and obstetric conditions, such as adenomyosis, ${ }^{11}$ postpartum hemorrhage, ${ }^{12}$ and CSP. ${ }^{13}$

Patients were placed in a flat position and routinely disinfected and covered with aseptic hole towels. After local anesthesia, the right femoral artery was punctured to place the catheter sheath, and the catheter was delivered and cannulated to the bilateral uterine arteries respectively. Then $50 \mathrm{mg}$ of Methotrexate (MTX), gelatin sponge granules, and gelatin sponge strips were injected via the left and right uterine arteries and embolized to them for flow blockage. After bilateral UAE, the uterine capillaries are still open, and the blood supply to the uterus is maintained through the capillaries and the surrounding collateral vessels, thereby avoiding ischemic and necrotic uterus. ${ }^{14}$

UAE for the treatment of CSP is safe and reliable. The present study aims to investigate the occurrence of moderate to severe pain in patients with CSP after UAE in Fujian Medical University Union Hospital, and then to provide a reference for the purposeful implementation of the necessary interventions on the influencing factors to reduce the pain, enhance the comfort of hospitalization, and improve the medical experience for patients.

\section{Materials and Methods \\ Study Subjects}

In the present study, a retrospective analysis was used to select 98 patients with a maximum age of 45 years, a minimum age of 21 years, and an average age of 33.16 \pm 5.05 years who experienced pain after UAE for CSP in the Fujian Medical University Union Hospital from January 2017 to December 2020 as the study population. The minimum gestation period was 35 days and the maximum was 96 days, with an average of $51.73 \pm 11.50$ days.

The diagnostic criteria of CSP referred to the ultrasound diagnostic criteria of CSP first proposed by Godin et $\mathrm{al}^{15}$ (1) No evidence of intrauterine pregnancy; (2) No evidence of pregnancy in the cervical canal; (3) Pregnancy sac visible in the anterior wall of the uterine isthmus; (4) Defective uterine muscle tissue between the gestational sac and the bladder; (5)Amenorrhea.

The inclusion criteria were as follows: (1) Patients with CSP confirmed by ultrasound or magnetic resonance image (MRI); (2) Patients with a previous history of cesarean section; (3) Patients with significantly elevated $\beta-$ HCG, which was consistent with weeks of menopause.

The exclusion criteria were as follows: (1) Patients with cervical pregnancy; (2) Patients with intrauterine pregnancy; (3) Patients with previous UAE for CSP; (4) Patients with pain caused by other diseases at the time of admission.

\section{Study Methods Specialty Data Collection}

Specialty data that might affect patient pain were included as factors in the present investigation, including the number of pregnancies, the number of miscarriages, days of gestation, duration of medication before UAE, HCG before curettage, the volume of the gestational sac, and hemorrhage after UAE. The volume of the gestational sac referred to the first color ultrasound findings on admission, hemorrhage after UAE was estimated by weighing, and the remaining data were obtained from the medical records, laboratory test results, and medical prescriptions for the patient.

\section{Evaluation Indicators}

The numerical rating scale (NRS) ${ }^{16}$ was adopted for the evaluation of patient pain after UAE. A scale of 0 to 10 was 
used to represent different degrees of pain. The grading standards were as follows: 0 for no pain, 1 to 3 for mild pain, 4 to 6 for moderate pain, 7 to 9 for severe pain, and 10 for critical pain. The time of pain onset referred to the period between the end of the UAE and the onset of pain back on the ward.

\section{Statistic Analysis}

The SPSS 23.0 software was adopted for data processing. Measurement data that satisfied the normal distribution were expressed as means and standard deviations, and those that failed to satisfy the normal distribution were expressed as medians. Countable data were expressed as percentages and number of cases, with the adoption of the $\chi^{2}$ test. Multiple linear regression analysis was used, and those statistically significant indicators in the univariate analysis were introduced for further analysis of the independent factors influencing the development of moderate to severe pain after UAE in patients with CSP. $P<0.05$ was considered statistically significant.

\section{Results}

1. The time and frequency of pain occurrence were analyzed in 36 patients with moderate to severe postoperative pain, and the results showed that 25 patients $(69.44 \%)$ had one occurrence of pain, 8 patients $(22.22 \%)$ had two occurrences, and 3 patients $(3.33 \%)$ had three or more occurrences. The time to the first onset of pain was calculated, and the results showed that the interquartile of the time to the first onset of pain in patients after surgery was $3.04(1.75,7.40)$ hours.

2. Univariate analysis of the occurrence of moderate to severe postoperative pain in patients with CSP undergoing UAE was conducted, and the results suggested that the number of pregnancies, number of miscarriages, HCG before curettage, duration of medication before UAE, and hemorrhage after UAE were not significantly correlated with the occurrence of moderate to severe pain after UAE (P > 0.05). Both the volume of gestational sac and days of gestation were responsible for the occurrence of moderate to severe pain $(\mathrm{P}<0.05)$, as shown in Table 1 .

3. Multivariate linear regression analysis was conducted with the nature of the pain as the dependent variable and the two statistically significant single factors in the univariate analysis as independent variables, ie, the volume of gestational sac and days of gestation. The results revealed that the volume of the gestational sac was the main influencing factor for the occurrence of

Table I The Analysis of Factors Influencing Postoperative Pain in Patients with Cesarean Scar Pregnancy Who Received Uterine Artery Embolization $(n=98)$

\begin{tabular}{|c|c|c|c|c|c|}
\hline \multicolumn{2}{|l|}{ Related Factors } & \multirow{2}{*}{$\begin{array}{l}\text { Moderate to Severe Pain } \\
\qquad \begin{array}{c}(\mathbf{n}=36, \%) \\
4(11.1) \\
6(16.7) \\
26(72.2)\end{array}\end{array}$} & \multirow{2}{*}{$\begin{array}{l}\text { Mild Pain+No Pain } \\
\qquad \begin{array}{c}(n=62, \%) \\
3(4.8) \\
18(29.1) \\
4 \mid(66.1)\end{array}\end{array}$} & \multirow{2}{*}{$\begin{array}{c}\chi^{2} \\
2.800\end{array}$} & \multirow{2}{*}{$\begin{array}{c}P \text {-value } \\
0.247\end{array}$} \\
\hline The number of pregnancies & $\begin{array}{c}2 \\
3 \\
>3\end{array}$ & & & & \\
\hline The number of miscarriages & $\begin{array}{c}0 \\
1 \\
2 \\
>2\end{array}$ & $\begin{array}{l}7(19.4) \\
14(38.9) \\
9(25.0) \\
6(16.7)\end{array}$ & $\begin{array}{l}10(16.1) \\
24(38.7) \\
14(22.6) \\
14(22.6)\end{array}$ & 0.592 & 0.898 \\
\hline The days of gestation & $\begin{array}{l}\leq 84 \\
>84\end{array}$ & $\begin{array}{c}33(91.7) \\
3(8.3)\end{array}$ & $\begin{array}{c}62(100.0) \\
0\end{array}$ & 5.330 & 0.021 \\
\hline $\begin{array}{l}\text { The time of curettage after } \\
\text { intervention (hours) }\end{array}$ & $\begin{array}{c}\leq 24 \\
>24, \leq 48 \\
>48\end{array}$ & $\begin{array}{c}23(63.9) \\
13(36.1) \\
0\end{array}$ & $\begin{array}{c}44(71.0) \\
18(29.0) \\
0\end{array}$ & 0.528 & 0.468 \\
\hline The HCG before curettage $(\mathrm{IU} / \mathrm{mL})$ & $\begin{array}{l}\leq 50,000 \\
>50,000\end{array}$ & $\begin{array}{l}16(44,4) \\
20(55.6)\end{array}$ & $\begin{array}{l}36(58.1) \\
26(41.9)\end{array}$ & 1.696 & 0.193 \\
\hline The volume of hemorrhage $(\mathrm{mL})$ & $\begin{array}{l}\leq 100 \\
>100\end{array}$ & $\begin{array}{c}35(97.2) \\
\text { I }(2.8)\end{array}$ & $\begin{array}{c}58(93.5) \\
4(6.5)\end{array}$ & 0.635 & 0.426 \\
\hline $\begin{array}{l}\text { The volume of the gestational sac } \\
\left(\mathrm{cm}^{3}\right)\end{array}$ & $\begin{array}{l}\leq 18 \\
>18\end{array}$ & $\begin{array}{l}29(80.6) \\
7(19.4)\end{array}$ & $\begin{aligned} & 61(98.4) \\
& \text { I }(1.6)\end{aligned}$ & 9.660 & 0.002 \\
\hline
\end{tabular}


moderate to severe pain after UAE $(P<0.05)$, which explained $8.3 \%$ of the total variance, as shown in Table 2 .

\section{Discussion}

\section{Moderate to Severe Pain Was Common in Patients with CSP After UAE}

For women who have had a cesarean section, a high level of caution should be exercised for the occurrence of CSP in a second pregnancy, and early intervention is necessary once the diagnosis is confirmed. ${ }^{17}$

The main principle of UAE for the treatment of CSP and postpartum hemorrhage ${ }^{3,18}$ is the intravascular injection of embolic material to directly cut off the blood supply to the target area of the uterine artery, resulting in ischemic necrosis of the lesion or embryonic tissue. Intravascular infusion of MTX increases the local drug concentration and enhances the embryo-killing effect. It has been reported in the literature that there is also a correlation between pain after UAE and factors such as embolization material, level of embolization, type of disease, and drugs used during the embolization. ${ }^{19}$

Among the 98 patients investigated in the present study, 36 cases had moderate to severe pain, an incidence of $36.7 \%$, similar to the incidence of $35.2 \%$ reported by Armstrong et al, ${ }^{20}$ which suggests that moderate to severe pain commonly occurs in patients with CSP after UAE. Post-UAE pain is acute pain that may develop into chronic pain in approximately $10 \%$ to $50 \%$ of patients if not treated promptly. ${ }^{21}$

Results in the present study revealed that $25.55 \%$ of cases had experienced two or more onsets of moderate to severe pain after UAE, and the time for the first occurrence of pain was around 3 hours. When patients returned to the ward after surgery, nursing staff should focus on the chief complaint of patients about 3 hours after surgery and timely intervention. Therefore, it was necessary to provide patients with effective and scientific pain care, ask them about the pain in a timely manner, communicate with them before the onset of pain, inform them about the operation of UAE, together with discussing the cause, nature, and location of the pain.

Patients should be instructed correctly to divert their attention, and learn self-suggestion, self-relaxation, and other methods to ensure they could cooperate with treatment with a positive attitude to improve the pain threshold, tolerance, and reduce the occurrence of chronic pain. In case of the occurrence of moderate to severe pain, patients should be treated with non-steroidal drugs as prescribed by the doctor, actively informed of the possible side effects, and the efficacy of the drugs should be observed. Patients should be advised to treat the pain correctly to relieve it and improve comfort. Based on the theory of accelerated rehabilitation surgery, bilateral lumbar block can be used for patients with high pain risk, which can not only effectively reduce pain, but also reduce the demand for analgesic drugs. ${ }^{22}$ A prospective study report pointed out that injection of lidocaine into uterine artery can reduce the pain after UAE and promote the rehabilitation of patients. $^{23}$ Therefore, appropriate preventive treatment can be taken timely according to the needs of patients to reduce the postoperative pain.

Table 2 Multivariate Linear Regression Analysis of the Factors Influencing Postoperative Pain in Patients with Cesarean Scar Pregnancy Who Received Uterine Artery Embolization

\begin{tabular}{|c|c|c|c|c|c|c|c|c|c|}
\hline \multirow[t]{2}{*}{$\begin{array}{l}\text { Independent } \\
\text { Variable }\end{array}$} & \multirow{2}{*}{$\begin{array}{c}\text { Non } \\
\text { Standardized } \\
\text { Coefficient }\end{array}$} & \multirow[t]{2}{*}{$\begin{array}{l}\text { Standardization } \\
\text { Coefficient Beta }\end{array}$} & \multirow[t]{2}{*}{$t$-value } & \multirow[t]{2}{*}{$P$-value } & \multicolumn{2}{|c|}{$\begin{array}{c}\text { 95\% Confidence } \\
\text { Interval }\end{array}$} & \multirow{2}{*}{$\begin{array}{c}\text { Adjusted } \\
\text { R-Square } \\
\text { value }\end{array}$} & \multirow[t]{2}{*}{ F-value } & \multirow[t]{2}{*}{$P$-value } \\
\hline & & & & & $\begin{array}{l}\text { Lower } \\
\text { Limit }\end{array}$ & $\begin{array}{l}\text { Upper } \\
\text { Limit }\end{array}$ & & & \\
\hline $\begin{array}{l}\text { Constant } \\
\text { (quantity) }\end{array}$ & 2.356 & & 8.259 & 0 & 1.789 & 2.922 & 0.083 & 5.387 & 0.006 \\
\hline $\begin{array}{l}\text { Gestational sac } \\
\text { volume }\end{array}$ & -0.478 & -0.271 & -2.241 & 0.027 & $-0.90 \mathrm{I}$ & -0.055 & & & \\
\hline $\begin{array}{l}\text { The days of } \\
\text { gestation }\end{array}$ & -0.200 & -0.071 & 0.590 & 0.556 & -0.873 & 0.473 & & & \\
\hline
\end{tabular}




\section{The Volume of the Gestational Sac and Days of Gestation Were the Influencing Factors in the Development of Moderate to Severe Pain in Patients with CSP After UAE}

The results in Table 1 show that there exists a strong correlation between the volume of the gestational sac, the days of gestation, and the development of moderate to severe postoperative pain in patients. The multivariate linear regression analysis in Table 2 demonstrates that the volume of the gestational sac was the main influencing factor for the development of moderate to severe pain $(\mathrm{P}<0.05)$. Since the isthmus of the uterus is thinner and less elastic due to previous scarring in patients with CSP, early intervention is needed to terminate the pregnancy once the gestational sac implants in this area, and there is always a risk of hemorrhage and uterine rupture as the gestational week increases. ${ }^{24}$ In patients with CSP, the volume of the gestational sac increases as the gestational week increases, and the blood circulation and the load on the organism gradually increase, intensifying the postoperative pain even when treated with UAE. This was consistent with the results reported by Liang Ning. ${ }^{25}$

To reduce the occurrence of moderate to severe postoperative pain in patients with CSP who underwent UAE, medical staff should consider the volume of the gestational sac and choose the best time to provide treatment that could improve the postoperative comfort of the patients.

In summary, patients with CSP who underwent UAE were prone to develop moderate to severe postoperative pain. The incidence was $36.7 \%, 69.44 \%$ of whom had only one pain. The volume of the gestational sac and days of gestation were the main factors influencing the occurrence of moderate to severe pain, with the volume of the gestational sac being the main influencing factor. Three hours after embolization was the peak period for the occurrence of moderate to severe pain. However, there were some limitations in the present study. The thickness of the scar was not collected, other factors that might cause pain in patients were not considered, and whether the number of c-sections had an effect on pain was not collected, which could be included in future studies.

In clinical care of patients with CSP who were to receive UAE, pain evaluation should be assessed in advance, taking the volume of the gestational sac and the days of gestation into account. Interventions should be implemented early to reduce pain and improve the health care experience for patients.

\section{Ethics Approval and Consent to Participate}

The study was conducted in accordance with the Declaration of Helsinki (as was revised in 2013). The study was approved by Ethics Committee of the Fujian Medical University Union Hospital. Written informed consent was obtained from all participants.

\section{Acknowledgments}

We are particularly grateful to all the people who have given us help on our article.

\section{Disclosure}

The authors declare that they have no competing interests.

\section{References}

1. Gao WJ. Clinical observation and nursing cooperation analysis of uterine artery embolization in the treatment of uterine scar pregnancy. Electron J Pract Clin Nurs Sci. 2019;4(46):70-71. [Article in Chinese]. Available from: https://kns.cnki.net/kcms/detail/ detail.asp $x$ dbcode $=$ CJFD $\&$ dbname $=$ CJFDLAST2020\&filename $=$ S L H L 201946064 \& u n i p lat for m = N Z K P T \& v= Ykd6R2hGl5uefwFZ6umm9abHOCrP6sE1dgz0wmtEoidXMJr5Dbv9 r16rB0CskHvY

2. Xie X, Kong BH. Gynecology and Obstetrics. 9th ed. Beijing: People's Medical Publishing House; 2018:80-81.

3. Li K, Dai Q. Differential diagnosis of cesarean scar pregnancies and other pregnancies implanted in the lower uterus by ultrasound parameters. Biomed Res Int. 2020;2020:8904507. doi:10.1155/2020/ 8904507

4. Hastuya. Application value of uterine artery embolization in the treatment of pregnancy at uterine scar after cesarean section. Chin J Modern Drug Appl. 2020;14(07):44-46. [Article in Chinese]. https://kns.cnki.net $/ \mathrm{kcms} /$ detail $/$ detail.aspx? dbcode $=$ CJFD\&dbname $=$ CJFDLAST2020\&filename $=$ ZWYY202007021\&uniplatform $=$ NZKPT\&v $=y B r B \% 25 \mathrm{mmd} 2 \mathrm{Fr} 212 \mathrm{r} \% 25 \mathrm{mmd} 2 \mathrm{BQn} 3 \mathrm{di} 18 \mathrm{FMB} 9 \mathrm{bGot} \%$ $25 \mathrm{mmd} 2 \mathrm{FYhgjoKiHsx}$ s A p A huU q \% 25 m m d 2 F y A \% 25mmd2FdDJTOo1MWCkGxv

5. Zhang WL, Zhang ZM, Feng CX. Application effect of uterine artery embolization in cesarean scar pregnancy patients. Chin Modern Med. 2020;27(11):116-119. [Article in Chinese]. Available from: https://kns.cnki.net $/ \mathrm{kcms} /$ detail $/$ detail.aspx?dbcode $=$ C J F D \& d b n a m e $=$ C J F D L A S T $2020 \&$ fi 1 e n a m e $=$ Z GUD 202011034 \& un i p 1 at for $\mathrm{m}=\mathrm{NZKK}$ T \& v = RMpCzeSTtexKR9UyHQBU5QFFtc2GjPJpICRSD9VMIFjpMjarLp p4kYadUeo\%25mmd2FPzAf

6. Long Y, Zhu H, Hu Y, Shen L, Fu J, Huang W. Interventions for non-tubal ectopic pregnancy. Cochrane Database Syst Rev. 2020;7 (7):CD011174. doi:10.1002/14651858.CD011174.pub2

7. Cooperative Group of Enhanced Recovery After Surgery. Consensus guidelines for enhanced recovery after gynecologic surgery. Chin J Obstet Gynecol. 2019;54(2):73-79. [Article in Chinese]. Available from: https://kns.cnki.net $/ \mathrm{kcms} /$ detail $/$ detail.aspx? dbcode $=$ C J F D \& d b n a m e $=$ C J F D Z H Y X \& fi 1 e $n$ a $m e=$ Z H F C $201902001 \&$ un i p lat for $m=N Z$ K P T \& v $=$ A He 0 g 52 QH1D 8 V c fuCS 1 dy 09 nm_GZVwAtwdY-h_ OuYJ3jheQzqspkSO0Z2nVGVxxU. 
8. Binkert CA, Hirzel FC, Gutzeit A, Zollikofer CL, Hess T. Superior hypogastric nerve block to reduce pain after uterine artery embolization: advanced Technique and comparison to epidural anesthesia. Cardiovasc Intervent Radiol. 2015;38(5):1157-1161. doi:10.1007/ s00270-015-1118-z

9. Reciti R, Ma L, Peng QJ. Clinical observation of the effect of preoperative anxiety on postoperative pain in cesarean scar pregnancy patients undergoing uterine artery embolization. $J$ Xinjiang Med Univ. 2018;41(03):311-314. [Article in Chinese]. Available from: https://kns.cnki.net $/ \mathrm{kcms} /$ detail $/$ detail.aspx?dbcode $=$ C J F D \& d b n a m e = C J F D L A S T 2018 \& fi 1 e n a me e XJYY $201803014 \&$ uniplatform $=$ NZKPT \&v $=$ MXuAq $\%$ 25mmd2BlTTKqIbHxRr1xlhJJH7Z99w0spMwfUaBOEYB0oho4AD RRwevFxgk27Arsw

10. Li YB. Nursing for cesarean scar pregnancy uterine artery embolizationcombined with uterine curettage experience. Electron $J$ Pract Clin Nurs Sci. 2016;1(12):100-101+103. [Article in Chinese]. Available from: https://kns.cnki.net $/ \mathrm{kcms} /$ detail/detail.aspx?dbcode $=$ C J F D \& d b n a m e $=$ C J F D L A S T 2017 \& fi 1 e n a m e $=$ S L H L $201612070 \&$ u n i p lat for m $=$ N Z K P T \& v = ek 7 P a 22 e I 9 AW Gi YuQUx\% 25 m m 2 BnCItF 3 Hq \% $25 \mathrm{~m} \mathrm{~m} \mathrm{~d} 2$ B L J E 8 P y o V d t u L F 1 h w u G u F h C \% 25mmd2FWA9VBa5VOMbZ

11. Pyra K, Szmygin M, Szmygin H, et al. Endovascular embolization as a treatment for symptomatic adenomyosis - results of preliminary study [published online ahead of print, 2021 Jul 15]. Ginekol Pol. 2021;10. doi:10.5603/GP.a2021.0136

12. Bernasconi M, Eggel-Hort B, Horsch A, et al. Paternal and maternal long-term psychological outcomes after uterine artery embolization for severe post-partum hemorrhage. Sci Rep. 2021;11(1):13990. doi:10.1038/s41598-021-92847-z

13. Ko HK, Shin JH, Ko GY, et al. Efficacy of prophylactic uterine artery embolization before obstetrical procedures with high risk for massive bleeding. Korean J Radiol. 2017;18(2):355-360. doi:10.3348/ kjr.2017.18.2.355

14. No authors listed. Uterine-artery embolisation or myomectomy for uterine fibroids? Drug Ther Bull. 2021;59(9):134. doi:10.1136/ dtb.2021.000042

15. Godin PA, Bassil S, Donnez J. An ectopic pregnancy developing in previous caesarean section scar. Fertil Steril. 1997;67(2):398-400. doi:10.1016/S0015-0282(97)81930-9

16. Hawker GA, Mian S, Kendzerska T, et al. Measures of adult pain: Visual Analog Scale for Pain (VAS Pain), Numeric Rating Scale for Pain (NRS Pain), McGill Pain Questionnaire (MPQ), Short-Form McGill Pain Questionnaire (SF-MPQ), Chronic Pain Grade Scale (CPGS), Short Form-36 Bodily Pain Scale (SF-36 BPS), and measure of Intermittent and Constant Osteoarthritis Pain (ICOAP). Arthritis Care Res. 2011;63 Suppl 11(S2):40-52.

17. Yang J, Zhang YF, Yao JJ, Zhang P. Clinical effect of uterine artery embolization in the treatment of scar pregnancy after cesarean section. J Ningxia Med Univ. 2017;39(08):916-918. [Article in Chinese]. Available from: https://kns.cnki.net $/ \mathrm{kcms} /$ detail $/$ detail. asp $x$ ? dbcode $=$ CJFD \&dbname $=$ CJFDLAST2017\&filename $=$ X N X Y $201708018 \&$ un i p lat for $m=N Z K P T \& v=$ WMdmU22q5iim4eWckxwSAW7GHsPNBTjlkVFQOm2soEdsHqJr F\%25mmd2Bcb8xuyAFMY12WW
18. Du MQ, Chen JM, Gao HY, et al. Clinical observation and nursing of uterine artery embolization in the treatment of uterine scar pregnancy. Modern Nurse. 2017;(04):79-81. [Article in Chinese]. Available from: https://kns.cnki.net $/ \mathrm{kcms} /$ detail/detail.aspx ?dbcode $=$ C J F D \& d b n a m e $=$ C J F D L A S T $2017 \&$ fi 1 e n a me $=$ D D Z T $201704038 \&$ un ip 1 at for $m=N Z$ K P T \& v $=$ 2SA ohX 59xEUxHSJgXhbs X 9S 5QpDj8yuxFvYhXS\% 25mmd2F6pvxoqsZGbuEJGVVUhw6H1A32

19. Wang LG, Hao Y. Cause analysis and nursing of abdominal pain after uterine artery embolization. Med Forum. 2011;15(01):44-45. [Article in Chinese]. Available from: https://kns.cnki.net/kcms/detail/detail. asp $\mathrm{dbcode}=\mathrm{CJFD} \& \mathrm{dbname}=\mathrm{CJFD} 2011 \&$ filen ame $=$ YXLT2 $01101026 \&$ un i p 1 at for m=NZKP T \& v = e T F o 48 G e a W J 3 y 6 p A x W W Z S S Z 3 w 5 O 5 p \% 25mmd2Ftcniiy5NeFuZILydTFDRZj0QDOQWUcVRct

20. Armstrong AA, Kroener L, Brower M, Al-Safi ZA. Analysis of reported adverse events with uterine artery embolization for leiomyomas. J Minim Invasive Gynecol. 2019;26(4):667-670.e1. doi:10.1016/j.jmig.2018.07.006

21. Ren H, Li MZ. Pain. J Nurs Train. 2011;26(5):387-389.

22. Ben-David B, Kaligozhin Z, Viderman D. Quadratus lumborum block in management of severe pain after uterine artery embolization. Eur J Pain. 2018;22(6):1032-1034. doi:10.1002/ ejp. 1171

23. Noel-Lamy M, Tan KT, Simons ME, Sniderman KW, Mironov O, Rajan DK. Intraarterial lidocaine for pain control in uterine artery embolization: a prospective, randomized study. J Vasc Interv Radiol. 2017;28(1):16-22. doi:10.1016/j.jvir.2016.10.001

24. Xiong P, Wu SM, Li DY. Diagnosis and treatment of lower uterine scar pregnancy after cesarean section by transvaginal color Doppler. Chin J Clin Ration Drug Use. 2017;10(7):154-155. [Article in Chinese]. Available from: https://kns.cnki.net $/ \mathrm{kcms} /$ detail/detail. asp $\mathrm{d}$ dbcode $=$ CJFD\&dbname $=$ CJFDLAST2017\&filename $=$ P L H Y $201707100 \&$ u n i p lat for m $=$ N Z K P T \& v = A3qPeD9xJYiUzr9YnhPAEtJMEpx6hCMY1jeiUXoIOpGvyffcMqot ZM91j0dNu83S

25. Liang N. Study on influencing factors and nursing countermeasures of pain after uterine artery embolization in patients with scar pregnancy. Modern Digest Intervent. 2019;A01(0442). [Article in Chinese]. Available from: http://jour.ucdrs.superlib.net/views/speci fic $/ 2929 /$ JourDetail.j sp? dx Number $=100280830609 \& \mathrm{~d}=$ DEBFDB23EFF56B0E65CD0D639E0E4649\&s $=. \%$ E7\% $\% 6 \% A 4 \%$ E7\%97\%95\%E5\%A6\%8A\%E5\%A8\%A0\%E6\%82\%A3\%E8\%80\% $85 \% \mathrm{E} 8 \% \mathrm{~A} 1 \% 8 \mathrm{C} \% \mathrm{E} 5 \% \mathrm{AD} \% 90 \% \mathrm{E} 5 \% \mathrm{AE} \% \mathrm{AB} \% \mathrm{E} 5 \% 8 \mathrm{~A} \% \mathrm{~A} 8 \%$ Е8\%84\%89\%Е6\%A0\%93\%Е5\%A1\%9E\%Е6\%9C\%AF\%Е6\%B2\% BB $\%$ E7\%96\%97\%E5\%90\%8E\%Е7\%96\%BC\%E7\%97\%9B\%Е5\% BD $\%$ B1\%E5\%93\%8D\%E5\%9B\%A0\%E7\%B4\%A0\%E5\%8F\%8A\% E5\%85\%B6\%E6\%8A\%A4\%E7\%90\%86\%E5\%AF\%B9\%E7\%AD\% $96 \% \mathrm{E} 7 \% \mathrm{~A} 0 \% 94 \% \mathrm{E} 7 \% \mathrm{~A} 9 \% \mathrm{~B} 6 \&$ ecode $=$ utf- 8 


\section{Publish your work in this journal}

The International Journal of General Medicine is an international, peer-reviewed open-access journal that focuses on general and internal medicine, pathogenesis, epidemiology, diagnosis, monitoring and treatment protocols. The journal is characterized by the rapid reporting of reviews, original research and clinical studies

across all disease areas. The manuscript management system is completely online and includes a very quick and fair peer-review system, which is all easy to use. Visit http://www.dovepress.com/ testimonials.php to read real quotes from published authors. 